\title{
THE LEVEL OF ORGANIZATIONAL
}

CULTURE AS A CONSTANT CHALLENGE FOR COMPANY MANAGEMENT

- AN EMPIRICAL RESEARCH

IN THE CZECH REPUBLIC AND POLAND

\author{
Marcela Sokolova, Vaclav Zubr, Anna Cierniak-Emerych, \\ Szymon T. Dziuba
}

\section{Introduction}

Due to the pressure of global competition, shortened product-life cycles and the increasing opportunity to imitate product designs or their elements, companies continuously focus on innovations as one of their main agenda in order to maintain their global or national competitiveness. Besides, these innovations are considered as an ultimate source of productivity improvement, the growth in sales volume, and the capability of a company in question to stay competitive on the global market (Liao, Hu, Chen, \& Lin, 2015). Companies perceive the need to continuously adapt, develop, and innovate as an economic necessity that results from global market pressures. The enhancement of product design and quality, accessorial technological services, their accessibility and reliability are no longer only seen as a benefit but rather an ultimate condition for the sustainability of company competitiveness. The steady upgrades in innovation capability (IC) for the deployment and commercialisation of new technologies had become rather an iron law in company culture than just the rational management choice. Therefore, the creation and dissemination of IC within the framework of company organization is a necessary precondition for strengthening competitiveness and succeeding on the global or national market (Steiber, 2018; Chang, Kraus, Rigtering, \& Eggers, 2017)

\section{Organizational Culture}

Organizational culture $(\mathrm{OC})$ is a concept, which is defined from many different though not necessarily incompatible perspectives. Schein, for instance, argues that the OC concept evinces a heuristic value for the explanation of those social phenomena (which appear in groups, occupations, organizations and other kinds of social units that have common histories) that are conventionally seen as incomprehensive and irrational (Schein, 2017). In this regard Schein defines culture as a pattern of shared fundamental assumptions learned by a group as it overcomes both external adaptation and internal integration obstacles, whereby group member use is efficient enough to be considered valuable and which is taught to new members as the right way of meandering through the equivalent future obstacles. OC comprises structured behaviour (especially leadership style), language, rituals, ceremonies, myths, heroes, etc. (Dubkēvič \& Barbars, 2011). It may be presented in simple ways which make it more visible and conscious. Most of the authors of management science emphasise that $\mathrm{OC}$ also includes a value system which is determinant in relation to the attitude (de Vries \& Miller, 1986; Vanaerde \& Journée, 2003; Hofstede \& Hofstede, 2005; Barrett, 2017).

Values are generally defined as special meanings of ideas and objects that are negotiated on a personal as well as organizational level (Dubkēvič \& Barbars, 2011). They determine the perception of social and cultural reality, human nature and interpersonal relationships. So, the attitude primarily shapes our evaluation of situations in the world around us and comprises a cognitive dimension (what is positive or negative), affective dimension (emotions and feelings), and behavioural dimension (social actions oriented towards other persons and objects) (Warr, 2002). 
The aim of this study is to examine the level of organizational culture (measured by Organizational Culture Index value of three organizational culture - supportive, innovative, bureaucratic) in the Czech Republic and Poland, i.e. to make a comparison; there is shared consent that $\mathrm{OC}$ provides the 'social glue' that provides companies with coherence, identity, and direction. In this regard, this section briefly overviews cultural types linked to the ways that $O C$ is aimed to be created. Handy (1993), for example, addresses the organizational phenomena that contribute to both the successes and failures of companies and identifies four fundamental culture types (which he calls power, role, task, and person). Together, these types constitute a framework for the study and exploration of OC. In his survey of 88 Japanese companies, Kono (1990) identifies five culture types which he designates as Vitalised, 'Follow the leader and vitalised', Bureaucratic, Stagnant, 'Follow the leader and stagnant'. Tian, Deng, Zhang, and Salmador (2018) whose culture research is based on theoretically derived bipolar dimensions, distinguish several patterns of how to respond to the existential questions at national level. Additionally, they also extend their search by examining corporate cultures by nationality. On the other hand, Warr's Organizational Culture Assessment Instrument (OCAI) (2002) develops a balanced evaluation method of the OC suitability without implying that one culture type is a priori more efficient than another.

We suggest that the OC's conventional conceptualisation is sometimes too vague, amorphous and incomprehensible in the context of most peoples' mundane activities and day-to-day engagements with their work life obstacles in companies. Therefore, we suggest emphasising such dimensions and aspects of OC which are much closer to the ordinary perspectives of company employees using the concepts of culture types, industrial types and sub-cultures. We believe that this approach would be more productive as it is more easily related to the perceptions and sentiments associated with involvement, attitude and behaviour, and facilitates knowledge sharing. In this regard we follow Wallach (1983) who conceptualises and operationalises three culture dimensions, namely, (1) supportive, (2) innovative, and (3) bureaucratic hospital cultures. Wallach's (1983) cultural dimensions are broadly accepted because they correspond with the differentiation in managerial practices (bureaucratic, innovative, and supportive) and evinces a higher degree of relevance for the health-care setting. Hence, this model is also used in this study of the role of OCs in the possibilities of the enhancement of company innovation competitiveness. The pro-innovative organizational culture is perceived as the organization's ability to innovate.

There are many variations of how to define or understand the term innovation. It could be said that most of relevant studies focus on innovation as a way of technological improvement, upgrading, and perfection of product development. Adler and Shenha (1990), for instance, define innovation as: (1) the capacity to create such items which are able to address market demands, (2) the capacity to utilise existing innovation to create items, (3) the capacity to produce new items or refresh existing items to address business sector demands, and (4) the capacity to acquire and use new technological innovation to open new opportunities. Although, some authors consider IC as a specific company asset. In our previous study, we also extended the scope of the innovation's significance from technological sphere to management domains. This research considers IC an integral part of the process whereby the company in question goes through various types of innovation in order to reach the general enhancement of its IC (Mohelská \& Sokolová, 2018).

\section{Research Objective and Methodology}

The research is focused on literature research and on comparison of the level of organizational culture in organizations in the Czech Republic and Poland.

\subsection{Objectives and Research Question}

The main study objective is to examine the level of organizational culture in the Czech Republic and Poland, i.e. to make a comparison.

To accomplish this objective, it is necessary to define several sub-steps:

- STEP1: Content analysis (Defining basic concepts and contexts related to organizational culture, identification of possible factors determining the level of organizational culture in the Czech Republic and Poland.). 
- STEP2: Comparison of the level of organizational culture in organizations in the Czech Republic and Poland and a deeper analysis of the obtained data.

- STEP3: Results summary and conclusions formulation.

A research question has been established in connection with the aim of this thesis which examines organizational culture in the Czech Republic and Poland:

RQ: In what extent do employees perceive the level of organizational culture in Czech and Polish organizations the same way, i.e. are there any differences in the countries or other partial characteristics such as gender, organization size and job position?

The following hypotheses need to be verified in order to find a response to the research question:

$\mathrm{H1}_{0}$ : There is no statistically significant difference in the organizational culture index in the Czech Republic and Poland.

$\mathbf{H 2}_{\mathbf{0}}$ : There is no statistically significant difference in the organizational culture index in the Czech Republic and Poland according to gender.

H3: $_{0}$ There is no statistically significant difference in the organizational culture index in the Czech Republic and Poland according to the organization's size.

H4$_{0}$ : There is no statistically significant difference in the organizational culture index in the Czech Republic and Poland according to job classification.

These hypotheses are formulated as zero hypotheses. In the following chapter, where the survey results are presented, the hypotheses are decomposed into partial and more specific hypotheses that can be statistically validated.

\subsection{The Research Methodology}

A standardised questionnaire evaluating organizational culture - the Czech translation of Wallach's Questionnaire (1983) Organizational Culture Index $(\mathrm{OCl})$ was used for the comparison. The main reasons for choosing this questionnaire for the study are that the questionnaire is generally recognized, the structure of the questionnaire analyses the organizational culture level and that the questionnaire is not significantly affected by social and technological development. Use of the Wallach's Questionnaire allows to compare the results internationally. Ellen J. Wallach differentiated organizational culture into three dimensions - bureaucratic, supportive, and innovative. Bureaucratic culture is characterised by a hierarchical structure of an organization where there is a clear line of authorities and is highly organised. Supportive culture, on the other hand, is oriented towards interpersonal relationships. It is described with mutual trust, encouragement and co-operation. Innovative culture is considered to be dynamic, it stimulates creative work, brings new challenges, and encourages risky behaviour. The quantitative questionnaire research between respondents from the Czech Republic and Poland was conducted. The questionnaire consists of 24 items describing the organization that are rated at Likert's four-point scale with answers from 0 (does not describe our organization) to 3 (describes our organization in most cases). The responses are evaluated for each organizational culture dimension (eight items per dimension), so we get an index of organizational culture for bureaucratic, innovative and supportive culture. From these results, it is possible to read how respondent perceive the level of the relevant type of organizational culture in the organization where they work. The questionnaire also included the basic three demographic issues - gender, age and the respondent's education level, and five questions concerning the characteristics of the organization where the respondent works - the organization's ownership (Czech ownership, foreign ownership, international corporation and public/governmental organizations), the size of organization (up to 50 employees, up to 250 employees, 500 employees and over 500 employees), and the respondent's position (manager - employee supervisory, employee without employee liability) and business area.

Although it was not possible to obtain a cross-sectional sample in the Czech Republic and Poland, we tried to create a sample of employees from different fields, profit and non-profit sectors. Data was collected through collaboration in a distance study with our college students when they were asked to fill out a questionnaire with their colleagues in the organization where they work. We started out with the fact that these students are working in 


\section{Business Administration and Management}

Tab. 1:

Composition of the surveyed sample of respondents - Czech Republic and Poland

\begin{tabular}{|c|c|c|c|c|}
\hline \multirow[b]{2}{*}{ Item } & \multicolumn{2}{|c|}{ Czech Republic } & \multicolumn{2}{|c|}{ Poland } \\
\hline & $\%$ & frequency & $\%$ & frequency \\
\hline \multicolumn{5}{|l|}{ Gender } \\
\hline Men & 45.73 & 675 & 49.17 & 177 \\
\hline Women & 54.27 & 801 & 50.83 & 183 \\
\hline \multicolumn{5}{|l|}{ Age } \\
\hline Under 30 & 35.57 & 525 & 36.11 & 130 \\
\hline $30-40$ & 29.20 & 431 & 42.22 & 152 \\
\hline $51-50$ & 21.41 & 316 & 16.39 & 59 \\
\hline 51 and above & 13.82 & 204 & 5.28 & 19 \\
\hline \multicolumn{5}{|l|}{ Education } \\
\hline Elementary educational level & 0.34 & 5 & 0.83 & 3 \\
\hline Skilled worker & 8.27 & 122 & 0.56 & 2 \\
\hline Secondary school & 45.05 & 665 & 7.22 & 26 \\
\hline Higher professional school & 5.69 & 84 & 0.83 & 3 \\
\hline Undergraduate (distance) learning & 9.42 & 139 & 1.11 & 4 \\
\hline University degree education & 31.23 & 461 & 89.44 & 322 \\
\hline \multicolumn{5}{|l|}{ Years of experience (tenure) } \\
\hline Under 5 years & 48.85 & 721 & 68.33 & 246 \\
\hline $5-10$ years & 27.24 & 402 & 21.11 & 76 \\
\hline $11-15$ years & 10.84 & 160 & 6.11 & 22 \\
\hline Over 15 years & 13.08 & 193 & 4.44 & 16 \\
\hline \multicolumn{5}{|l|}{ Organization ownership } \\
\hline Local owner & 42.82 & 632 & 60.00 & 216 \\
\hline Foreign owner & 22.97 & 339 & 5.28 & 19 \\
\hline International corporation & 13.55 & 200 & 28.61 & 103 \\
\hline Public/governmental organization & 20.66 & 305 & 6.11 & 22 \\
\hline \multicolumn{5}{|l|}{ Organization size } \\
\hline Up to 50 employees & 34.62 & 511 & 35.56 & 128 \\
\hline Up to 250 employees & 26.02 & 384 & 21.11 & 76 \\
\hline Up to 500 employees & 10.98 & 162 & 10.56 & 38 \\
\hline Over 500 employees & 28.39 & 419 & 32.78 & 118 \\
\hline \multicolumn{5}{|l|}{ Job level } \\
\hline Manager/supervisory responsibility employee & 28.12 & 415 & 84.44 & 304 \\
\hline Non-supervisory responsibility employee & 71.88 & 1,061 & 15.56 & 56 \\
\hline
\end{tabular}


different types of organizations. In the Czech Republic, data collection took place in the first half of 2017 (this was the third survey of this kind (2013 and 2015) and at the turn of 2017 and 2018 in Poland.

The obtained data was evaluated using Microsoft Excel 2016 and IBM SPSS v. 24. Descriptive statistics tools, correlation and nonparametric Mann-Whitney U-test were used to evaluate the data at significance level $p=0.05$. As a dependent variable, the type of organizational culture (bureaucratic, innovative and supportive) was chosen in this test.

In the questionnaire survey's framework, 1,574 questionnaires were received in the Czech Republic, 1,476 questionnaires were processed (98 questionnaires were excluded from further processing due to various errors or the questionnaire's incompleteness.) 433 questionnaires were received in Poland and 360 questionnaires were included in the evaluation for the same reason as the Czech questionnaires (73 questionnaires were excluded). Since it has been a long-term study in the Czech Republic, more respondents were recruited, in Poland it was the first survey within the co-operation - pilot version.

A more detailed description of the surveyed sample of respondents is given in Tab. 1.

It is clear from these characteristics that a narrower group was examined in Poland, as it was mainly regarding respondents under the age of 40 , university educated in management positions. From this viewpoint, the respondents' sample in the Czech Republic was more representative. The section devoted to results will examine how this fact affects the survey results.

\subsection{Work Limitations}

The research has several limitations. The main one is respondent selection, as the whole territory of the Czech Republic and Poland is not covered from a geographic viewpoint. However, this deficiency is not so crucial, as both the Czech Republic and Poland currently have a relatively homogeneous socio-economic composition. Another survey limitation is the composition of respondents in terms of age, highest education achieved and employment position (as mentioned above). Despite the limitations, we are convinced that our data provides results that increase our knowledge of organizational culture levels in the Czech Republic and Poland.

\section{Research Result Evaluation}

Now the main findings, or verified hypotheses, will be presented. Firstly, the main hypothesis is examined, which concerns comparison of the organizational culture index in the Czech Republic and Poland.

\subsection{Comparison of the Organizational Culture Index in the Czech Republic and Poland}

$\mathrm{H}_{0}$ : There is no statistically significant difference in the organizational culture index in the Czech Republic and Poland.

The main hypothesis was broken-down into three parts, where it is verified whether there is a statistically significant difference between the different types of organizational culture in the Czech Republic and Poland.

- H1.1. There is no statistically significant difference in the bureaucratic organizational culture index in the Czech Republic and Poland.

- H1.2. There is no statistically significant difference in the innovative organizational culture index in the Czech Republic and Poland.

- H1.3. There is no statistically significant difference in the supporting organizational culture index in the Czech Republic and Poland.

At the top of Tab. 2 there are Organizational Culture Index values for individual dimensions in the Czech Republic and Poland. A certain difference in results can be seen from the index itself. Respondents in the Czech Republic evaluate organizational culture more as bureaucratic $(15,334)$ or supportive $(14,584)$, less respondents indicate it as innovative $(11,814)$. In Poland, this is basically the opposite. The highest index belongs to innovative culture $(15,164)$, then supportive $(14,858)$ and finally bureaucratic $(14,700)$ the absolute differences in indices are not as significant as in the Czech Republic. The distribution of individual value frequencies of individual dimensions in the organizational culture index in the Czech Republic and Poland is shown in the following charts (Figs. 1 and 2).

At the bottom of the table are the performed tests results (verification of partial hypotheses). Based on these results it can be stated that there is a statistically significant difference of $5 \%$ in the organizational culture index regarding innovative culture in the Czech 


\section{Business Administration and Management}

Tab. 2: $\begin{aligned} & \text { Organizational culture index in the Czech Republic and Poland - hypotheses } \\
& \text { results }\end{aligned}$
\begin{tabular}{l|r|r|r} 
& \multicolumn{2}{c}{ Organization culture index - total } \\
\hline & Bureaucratic & Innovative & \multicolumn{1}{c}{ Supportive } \\
\hline Czech Republic & 15.334 & 11.814 & 14.584 \\
\hline Poland & 14.700 & 15.164 & 14.858 \\
\hline & \multicolumn{4}{|c}{ Hypothesis test } \\
\hline Mann-Whitney U & $249,769.500$ & $145,930.500$ & $251,872.500$ \\
\hline Wilcoxon W & $314,749.500$ & $1,235,956.500$ & $1,341,898.500$ \\
\hline Z & -1.769 & -13.314 & -1.535 \\
\hline Asymp. Sig. (2-tailed) & 0.077 & 0.000 & 0.125 \\
\hline & & & Source: own
\end{tabular}

Republic and Poland - only this hypothesis has been confirmed. At a higher significance level, a certain difference can also be identified in the bureaucratic dimension.

Based on the results, the zero hypothesis $\mathrm{H} 1.2_{0}$ was rejected and an alternative hypothesis was adopted $\mathrm{H} 1.2_{1}$. There is a statistically significant difference in the innovative organizational culture index in the Czech Republic.

Due to the composition of respondents in Poland, especially regarding university-

\section{Fig. 1: Distribution of results in the Czech Republic - organizational culture index}

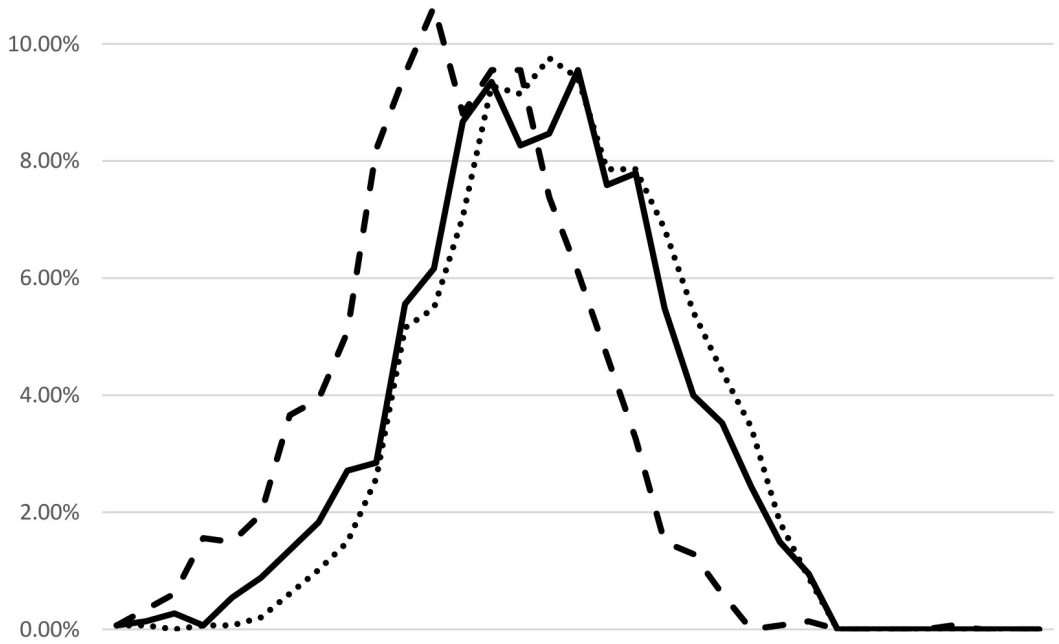






\section{Fig. 2: Distribution of results in Poland - organizational culture index}

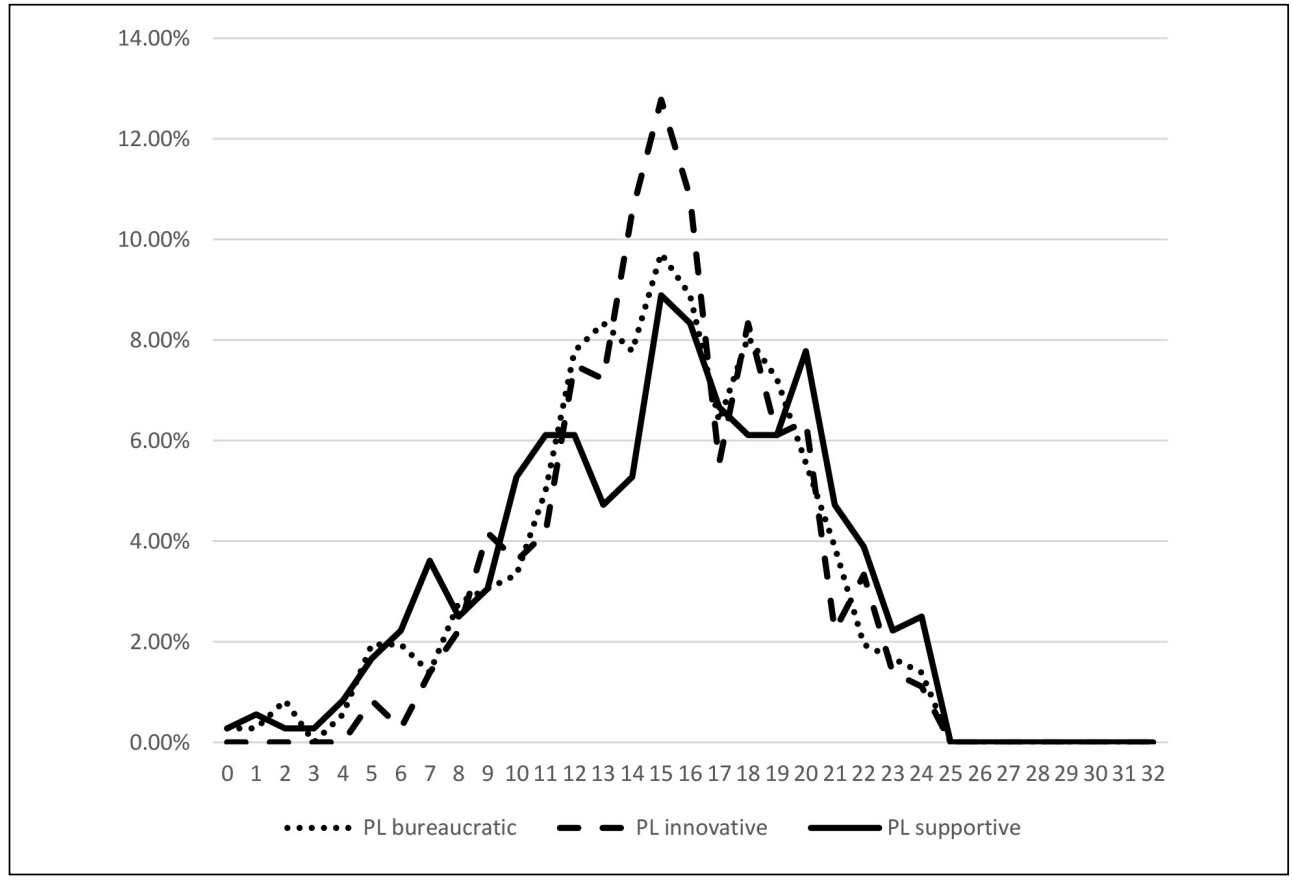

Source: own

educated respondents in management positions, subsequently, whether this fact had an impact on the resulting organizational culture index was verified. As the question is whether the index of organizational culture in the innovative culture (dimension) in Poland is influenced precisely by the fact that most respondents in Poland are university-educated and therefore are in positions where they have more freedom, they can initiate changes; they can be more creative, etc.

Therefore, whether education had an impact on the organizational culture index was verified. The results were compared only for university-educated respondents in the Czech Republic and Poland (see Tab. 3). From these results, we can see that if we compare only university-educated respondents in the Czech Republic and Poland, the result will be the same - the statistically significant difference in the innovative dimension is confirmed. Similarly, the Job level characteristic was verified.
Therefore, we can compare obtained data, as there is no proof that differences in the characteristics of the examined samples influence the results themselves - the organizational culture indexes of the individual dimensions.

\subsection{Organizational Culture Index Comparison in the Czech Republic and Poland - by Gender}

$\mathrm{H}_{0}$ : There is no statistically significant difference in the organizational culture index in the Czech Republic and Poland by gender.

- H2.10 There is no statistically significant difference in the bureaucratic organizational culture index by gender in the Czech Republic / Poland.

- H2.20 There is no statistically significant difference in the innovative organizational culture index by gender in the Czech Republic / Poland. 


Tab. 3: $\begin{aligned} & \text { Index of organizational culture in the Czech Republic and Poland } \\
& \text { - higher education }\end{aligned}$
\begin{tabular}{l|r|r|r} 
& \multicolumn{2}{c}{ Organization culture index - university degree education } \\
\hline & Bureaucratic & \multicolumn{1}{c}{ Innovative } & \multicolumn{1}{c}{ Supportive } \\
\hline Czech Republic & 15.562 & 11.983 & 15.069 \\
\hline Poland & 14.649 & 15.230 & 14.975 \\
\hline & \multicolumn{4}{|c|}{ Hypothesis test } \\
\hline Mann-Whitney U & $67,166.000$ & $41,187.500$ & $73,465.500$ \\
\hline Wilcoxon W & $119,169.000$ & $147,678.500$ & $179,956.500$ \\
\hline Z & -2.271 & -10.636 & -0.243 \\
\hline Asymp. Sig. (2-tailed) & 0.023 & 0.000 & 0.808 \\
\hline & & & Source: own
\end{tabular}

- H2.3. There is no statistically significant difference in the supportive organizational cultures index by gender in the Czech Republic / Poland.

Tab. 4 lists the test results regarding whether the organizational culture index is influenced by the respondent's gender. A statistically significant difference of $5 \%$ was only demonstrated in the innovative dimension $(p=0.025)$, and only in the Czech Republic. Men in the Czech Republic evaluate organizational culture as innovative with an average index value of 12,127 , compared with women with an average value of an organizational culture index of 11,549 . For the other dimensions in the Czech Republic and Poland the influence of gender was not proven.

Based on these results, the zero hypothesis $\mathrm{H} 2.2_{0}$ was rejected and an alternative hypothesis was adopted $\mathrm{H} 2.2_{1}$. There is a statistically significant difference in the innovation organizational culture index by gender in the Czech Republic.

\subsection{Organizational Culture Index Comparison in the Czech Republic and Poland - by Organization Size}

For further processing, the organizations where the respondents work are divided into two groups - up to 250 employees (including) and over 250 employees.

$\mathrm{H}_{0}$ : There is no statistically significant difference in the organizational culture index in the Czech Republic and Poland according to organization size.

- H3.1. There is no statistically significant difference in the bureaucratic organizational

\begin{tabular}{|c|c|c|c|c|c|c|}
\hline \multirow[t]{3}{*}{ Tab. 4: } & $\begin{array}{l}\text { tional cultu } \\
\text { eses result }\end{array}$ & index ir & le Czech F & ublic and & land by & der \\
\hline & \multicolumn{3}{|c|}{$\begin{array}{c}\text { Organization culture index } \\
\text { Czech Republic }\end{array}$} & \multicolumn{3}{|c|}{$\begin{array}{c}\text { Organization culture index } \\
\text { Poland }\end{array}$} \\
\hline & Bureaucratic & Innovative & Supportive & Bureaucratic & Innovative & Supportive \\
\hline Men & 15.287 & 12.127 & 14.643 & 14.621 & 15.305 & 14.977 \\
\hline \multirow[t]{2}{*}{ Women } & 15.373 & 11.549 & 14.534 & 14.776 & 15.027 & 14.743 \\
\hline & \multicolumn{3}{|c|}{ Hypothesis test } & \multicolumn{3}{|c|}{ Hypothesis test } \\
\hline Mann-Whitney U & $268,044.000$ & $252,054.500$ & $264,637.000$ & $15,587.500$ & $15,603.500$ & $16,065.000$ \\
\hline Wilcoxon W & $496,194.000$ & $573,255.500$ & $585,838.000$ & $31,340.500$ & $32,439.500$ & $32,901.000$ \\
\hline$Z$ & -0.282 & -2.248 & -0.701 & -0.617 & -0.602 & -0.132 \\
\hline Asymp. Sig. (2-tailed) & 0.778 & 0.025 & 0.484 & 0.537 & 0.547 & 0.895 \\
\hline
\end{tabular}




\begin{tabular}{|c|c|c|c|c|c|c|}
\hline \multirow[t]{3}{*}{ Tab. 5: } & \multirow{2}{*}{\multicolumn{3}{|c|}{$\begin{array}{l}\text { Organization culture index } \\
\text { Czech Republic }\end{array}$}} & \multirow{2}{*}{\multicolumn{3}{|c|}{$\begin{array}{l}\text { Organization culture index } \\
\text { Poland }\end{array}$}} \\
\hline & & & & & & \\
\hline & Bureaucratic & Innovative & Supportive & Bureaucratic & Innovative & Supportive \\
\hline Up to 250 & 14.546 & 11.734 & 14.860 & 13.485 & 15.314 & 15.466 \\
\hline \multirow[t]{2}{*}{ Over 251} & 16.547 & 11.936 & 14.158 & 16.288 & 14.968 & 14.064 \\
\hline & \multicolumn{3}{|c|}{ Hypothesis test } & \multicolumn{3}{|c|}{ Hypothesis test } \\
\hline Mann-Whitney U & $182,189.000$ & $253,711.000$ & $234,088.000$ & $10,279.000$ & $14,989.000$ & $13,439.500$ \\
\hline Wilcoxon W & $583,149.000$ & $654,671.000$ & $403,159.000$ & $31,189.000$ & $27,235.000$ & $25,685.500$ \\
\hline$z$ & -9.753 & -0.788 & -3.247 & -5.771 & -0.947 & -2.532 \\
\hline Asymp. Sig. (2-tailed) & 0.000 & 0.431 & 0.001 & 0.000 & 0.344 & 0.011 \\
\hline
\end{tabular}

culture index according to the size of organization in the Czech Republic / Poland.

- H3.2. There is no statistically significant difference in the innovative organizational culture index according to the size of organization in the Czech Republic / Poland.

- H3.3o There is no statistically significant difference in the supportive organizational culture index according to the size of organization in the Czech Republic / Poland.

From the results shown in Tab. 5, we can see that the organization size already has a more significant influence on the organizational culture evaluation. This impact has not only been demonstrated in an innovative culture (dimension). On the contrary, a significant statistical difference was demonstrated in bureaucratic culture both in the Czech Republic and in Poland. Respondents working in organizations with over than 251 employees perceive organizational culture as more bureaucratic than in smaller organizations. This fact could have been assumed as larger organizations need to have far more sophisticated management systems.

By contrast, respondents from smaller organizations see their organizations as more supportive. This proved to be the same in both the Czech Republic and Poland.

Based on these results, the zero hypothesis $\mathrm{H} 3.1_{0}$ was rejected and an alternative hypothesis was adopted $\mathrm{H} 3.1_{1}$ There is a statistically significant difference in the bureaucratic organizational culture index according to organization size in the Czech Republic and Poland. Furthermore, based on the results, the zero hypotheses $\mathrm{H} 3.3_{0}$ was rejected and an alternative hypothesis was adopted. H3.3, There is a statistically significant difference in the supporting organizational culture index according to organization size in the Czech Republic and Poland. The H3.2 $2_{0}$ hypothesis in the Czech Republic and Poland was accepted.

\subsection{Organizational Culture Index Comparison in the Czech Republic and Poland - by Job Classification}

$\mathrm{H}_{0}$ : There is no statistically significant difference in the organizational culture index in the Czech Republic and Poland according to the job classification.

- H4.1. There is no statistically significant difference in the bureaucratic organizational culture index according to the job classification in the Czech Republic / Poland.

- H4.2 $2_{0}$ There is no statistically significant difference in the innovative organizational culture index according to the job classification in the Czech Republic / Poland.

- H4.3. There is no statistically significant difference in the supportive organizational culture index according to the job classification in the Czech Republic / Poland.

According to the hypotheses results (Tab. 6) regarding the respondent's employment, it could be said that statistically significant differences are demonstrated for all organizational dimensions in the Czech Republic. In Poland, on the contrary, they are not proven. However, these conclusions should still be verified because there were more respondents in the Czech Republic in the 


\begin{tabular}{l|r|r|r|r|r|r|r} 
Tab. 6: & $\begin{array}{l}\text { Organizational culture index in the Czech Republic and Poland by job } \\
\text { classification - hypotheses results }\end{array}$ \\
& \multicolumn{3}{|c|}{$\begin{array}{r}\text { Organization culture index } \\
\text { Czech Republic }\end{array}$} & \multicolumn{3}{c}{$\begin{array}{c}\text { Organization culture index } \\
\text { Poland }\end{array}$} \\
\hline & Bureaucratic & Innovative & Supportive & Bureaucratic & Innovative & Supportive \\
\hline Employees & 15.226 & 11.494 & 14.324 & 13.661 & 14.607 & 14.750 \\
\hline Managers & 15.610 & 12.631 & 15.248 & 14.891 & 15.266 & 14.878 \\
\hline & \multicolumn{2}{|r|}{ Hypothesis test } & & Hypothesis test \\
\hline Mann-Whitney U & $206,960.500$ & $185,882.500$ & $193,279.500$ & $7,539.000$ & $7,846.000$ & $8,390.000$ \\
\hline Wilcoxon W & $770,351.500$ & $749,273.500$ & $756,670.500$ & $9,135.000$ & $9,442.000$ & $9,986.000$ \\
\hline Z & -1.798 & -4.670 & -3.661 & -1.363 & -0.934 & -0.171 \\
\hline Asymp. Sig. (2-tailed) & \multicolumn{2}{|c|}{0.072} & 0.000 & 0.000 & 0.173 & 0.350 & 0.864 \\
\hline
\end{tabular}

Source: own

Employee category and in Poland this was quite the opposite. The highest organizational culture index was achieved by bureaucratic culture for both employees and managers. The greatest consensus of employees and managers is in supporting culture in Poland.

Based on these results, the zero hypotheses $\mathrm{H} 4.2_{0}$ was rejected and the alternative hypothesis $\mathrm{H} 4.2_{1}$ was adopted. There is a statistically significant difference in the innovative organizational culture index according to job classification in the Czech Republic. At the same time, the zero hypothesis $\mathrm{H} 4.3_{0}$ was rejected and an alternative hypot $\mathrm{h}_{\mathrm{h}}$ esis was adopted $\mathrm{H} 4.3_{1}$ There is a statistically significant difference in the supportive organizational culture index according to job classification in the Czech Republic.

\section{Conclusions}

Each type of organizational culture is characterised by certain types of competing values that describe the Human Resource Management environment (Cameron \& Quinn, 1999). In terms of typology, this theory is very similar to that of Wallach (Wallach, 1983). In our survey organizational culture in the Czech Republic and in Poland was measured by using Wallach 24-item Organizational Culture Index $(\mathrm{OCI})$, which breaks down cultures into three dimensions - bureaucratic, innovative and supportive. Using a four-point scale (1 = Does not describe my organization, to $4=$ Describes my organization for the majority of the time), respondents were asked to assess how well the adjectives describe their company. $\mathrm{OCI}$ was used as a test and retest method for OCAI. This instrument allows determining the dominating cultural type and the effectiveness.

Our results show that innovative culture is a better model than bureaucratic or supportive culture. As far as managerial practice is concerned, the results suggest that managers should develop an innovative and supportive culture. It was discovered that there are statistically significant differences in innovative organizational culture index evaluation between the Czech Republic and Poland. The question of further investigation is how this difference is caused. According to the observed characteristics, no clear reason has been identified, the search for this difference will be the object of further investigation. One of the reasons may be some national differences (different perceptions and assessments of reality). In addition, statistically significant difference was observed in the organizational culture index evaluation, mainly depending on the organization's size and on the respondent's job position in the Czech Republic. The statistically significant difference in the organizational culture index evaluation in Poland was demonstrated depending on the organization's size.

The paper was written with the support of the specific project 2019 grant "Determinants of Cognitive Processes Impacting the Work Performance" granted by the University of Hradec Králové, Czech Republic and thanks to help of student Majid Ziaei Nafchi. 


\section{References}

Adler, P. S., \& Shenhar, A. (1990). Adapting Your Technological Base: The Organizational Challenge. Sloan Management Review, 32(1), 25-37.

Barrett, R. (2017). The values-driven organization: cultural health and employee wellbeing as a pathway to sustainable performance (2nd ed.). New York, NY: Routledge.

Cameron, K. S., \& Quinn, R. E. (1999). Diagnosing and changing organizational culture. Reading: Addison-Wesley.

Chang, M. L., Kraus, S., Rigtering, J. P. C., \& Eggers, F. (2017). Entrepreneurial orientation, strategic planning and firm performance: the impact of national cultures. European Journal of International Management, 11(3), 301. https://doi.org/10.1504/EJIM.2017.10004231.

de Vries, M. F. R. K., \& Miller, D. (1986). Personality, Culture, and Organization. The Academy of Management Review, 11(2), 266-279. https://doi.org/10.2307/258459.

Dubkēvič, L., \& Barbars, A. (2011). Role of organizational culture and leadership in company's efficiency: reserch papper. Saarbrücken: LAP Lambert Academic.

Handy, C. B. (1993). Understanding organizations. New York: Oxford University Press.

Hofstede, G. H., \& Hofstede, G. J. (2005). Cultures and organizations: software of the mind (2nd ed.). New York: McGraw-Hill.

Kono, T. (1990). Corporate culture and long-range planning. Long Range Planning, 23(4), 9-19. https://doi.org/10.1016/00246301(90)90148-W.

Liao, S., Hu, D., Chen, C.-C., \& Lin, Y.-L. (2015). Comparison of competing models and multi-group analysis of organizational culture, knowledge transfer, and innovation capability: an empirical study of the Taiwan semiconductor industry. Knowledge Management Research \& Practice, 13(3), 248-260. https://doi. org/10.1057/kmrp.2013.46.

Mohelska, H., \& Sokolova, M. (2018). Management Approaches for Industry 4.0 - The Organizational Culture Perspective. Technological and Economic Development of Economy, 24(6), 2225-2240. https://doi. org/10.3846/tede.2018.6397.

Mohelská, H., \& Sokolová, M. (2018). Trends in the Development of Organizational Culture - A Case Study in the Czech Republic. Transformations in Business \& Economics, 17(1/43), 50-63.
Qin, J., Liu, Y., \& Grosvenor, R. (2016). A Categorical Framework of Manufacturing for Industry 4.0 and Beyond. Procedia CIRP, 52, 173-178. https://doi.org/10.1016/j. procir.2016.08.005.

Schein, E. H. (2017). Organizational culture and leadership (5th ed.). Hoboken, New Jersey: Wiley.

Steiber, A. (2018). Management Characteristics of Top Innovators in Silicon Valley. In A. Steiber (Ed.), Management in the Digital Age (pp. 23-43). Cham: Springer International Publishing. https://doi. org/10.1007/978-3-319-67489-6 4.

Tian, M., Deng, P., Zhang, Y., \& Salmador, M. P. (2018). How does culture influence innovation? A systematic literature review. Management Decision, 56(5), 1088-1107. https://doi.org/10.1108/MD-05-2017-0462.

Vanaerde, P., \& Journée, M. (2003). Cultuurverandering. Antwerpen: De Boeck.

Wallach, E. J. (1983). Individuals and organizations: The cultural match. Training and Development Journal, 37(2), 28-36.

Warr, P. (Ed.). (2002). Psychology at work (5th ed.). London: Penguin Books.

Assoc. Prof. Ing. Marcela Sokolova, Ph.D. University of Hradec Kralove Faculty of Informatics and Management Department of Management Czech Republic marcela.sokolova@uhk.cz

Ing. Vaclav Zubr, Ph.D. University of Hradec Kralove Faculty of Informatics and Management Department of Management Czech Republic vaclav.zubr@uhk.cz

Prof. Anna Cierniak-Emerych, Ph.D. Wroclaw University of Economics Faculty of Engineering and Economics Department of Labour and Capital Poland anna.cierniak-emerych@ue.wroc.pl

Ing. Szymon T. Dziuba, Ph.D. Wroclaw University of Economics Faculty of Engineering and Economics Department of Labour and Capital Poland szymon.dziuba@ue.wroc.pl 


\title{
Abstract
}

\section{THE LEVEL OF ORGANIZATIONAL CULTURE AS A CONSTANT CHALLENGE FOR COMPANY MANAGEMENT - AN EMPIRICAL RESEARCH IN THE CZECH REPUBLIC AND POLAND}

\author{
Marcela Sokolova, Vaclav Zubr, Anna Cierniak-Emerych, Szymon T. Dziuba
}

Organizational culture (OC) is a concept, which is defined from many different perspectives. For example, Schein defines culture as a pattern of shared fundamental assumptions learned by a group as it overcomes both external adaptation and internal integration obstacles, whereby group member use is efficient enough to be considered valuable and which is taught to new members as the right way of meandering through the equivalent future obstacles. According to Dubkēvič and Barbars OC comprises structured behaviour (especially leadership style), language, rituals, ceremonies, myths, heroes, etc. The aim of this study is to examine the level of organizational culture in the Czech Republic and Poland, i.e. to make a comparison. In the questionnaire survey's framework, 1,574 questionnaires were received in the Czech Republic, 1,476 questionnaires were processed, 433 questionnaires were received in Poland and 360 questionnaires were included in the evaluation for the same reason as the Czech questionnaires. Since it has been a long-term study in the Czech Republic, more respondents were recruited, in Poland it was the first survey within the co-operation - pilot version. The obtained data was evaluated using Microsoft Excel 2016 and IBM SPSS v. 24. Descriptive statistics tools, correlation and nonparametric Mann-Whitney U-test were used to evaluate the data at significance level $p=0.05$. The results show that innovative culture is a better model than bureaucratic or supportive culture. Managers should develop an innovative and supportive culture. There are statistically significant differences in innovative organizational culture index evaluation between the Czech Republic and Poland. Statistically significant difference was observed in the organizational culture index evaluation, mainly depending on the organization's size and on the respondent's job position in the Czech Republic. The statistically significant difference in the organizational culture index evaluation in Poland was demonstrated depending on the organization's size.

Key Words: Organizational culture, Czech Republic, Poland, Wallach.

JEL Classification: M12, M14.

DOI: 10.15240/tul/001/2019-1-010 